\title{
Alcohol and relatively pure cannabis use, but not schizotypy, are associated with cognitive attenuations
}

\author{
Daniela A. Herzig ${ }^{1,2,3}$ *, David J. Nutt ${ }^{4}$ and Christine Mohr ${ }^{1,5}$ \\ ${ }^{1}$ Department of Experimental Psychology, University of Bristol, Bristol, UK \\ ${ }^{2}$ Institute for Response-Genetics, University of Zurich, Kilchberg, Switzerland \\ ${ }^{3}$ Clienia AG Littenheid, Littenheid, Switzerland \\ ${ }^{4}$ Neuropsychopharmacology Unit, Imperial College London, London, UK \\ ${ }^{5}$ Faculté des Sciences Sociales et Politiques, Institut de Psychologie, Université de Lausanne, Lausanne, Switzerland
}

\section{Edited by:}

Caroline Gurvich, Monash University,

Australia

\section{Reviewed by:}

John Gigg, University of Manchester, UK

Bernhard J. Mitterauer,

Volitronics-Institute for Basic

Research Psychopathology and Brain

Philosophy, Austria

*Correspondence:

Daniela A. Herzig, Clienia AG

Littenheid, Littenheid, Switzerland

e-mail: daniela.herzig@clienia.ch
Elevated schizotypy relates to similar cognitive attenuations as seen in psychosis and cannabis/polydrug use. Also, in schizotypal populations cannabis and polydrug (including licit drug) use are enhanced. These cognitive attenuations may therefore either be a behavioral marker of psychotic (-like) symptoms or the consequence of enhanced drug use in schizotypal populations. To elucidate this, we investigated the link between cognitive attenuation and cannabis use in largely pure cannabis users (35) and non-using controls (48), accounting for the potential additional influence of both schizotypy and licit drug use (alcohol, nicotine). Cognitive attenuations commonly seen in psychosis were associated with cannabis and alcohol use, but not schizotypy. Future studies should therefore consider (i) non-excessive licit substance use (e.g., alcohol) in studies investigating the effect of cannabis use on cognition and (ii) both enhanced illicit and licit substance use in studies investigating cognition in schizotypal populations.

Keywords: polydrug use, licit drug use, cognition, schizotypy, psychosis-proneness

\section{INTRODUCTION}

Cannabis sativa (marijuana) is currently the most widely used illegal substance in Europe (1). Past year cannabis use was reported by about $11.2 \%$ of all $15-34$ year olds (1). This elevated prevalence rate (when compared to other illicit drug use) is concerning, because cannabis use might go along with both cognitive attenuation $(2,3)$ and mental health problems, in particular psychosis (4-9). Yet, only a minority of cannabis users (CU) will develop psychotic illnesses $(5-7,10)$. Therefore, other factors likely influence adverse consequences associated with cannabis use $(9,11)$.

Here, we focused on the supposedly negative implications of cannabis use on cognitive functioning while accounting for individuals' schizotypy and associated licit drug use. We did so based on the following reasoning. On the one hand, relatively pure $\mathrm{CU}$ (i.e., no regular drug use other than marihuana, cigarettes, or alcohol) have attenuated cognitive functioning compared to nonusers (3), e.g., in verbal working memory (12), verbal short-term memory (13), and mental flexibility $(3,14)$. On the other hand, as detailed below, schizotypal personality features are not only part of the psychosis dimension but also associate with cognitive attenuations, cannabis use, as well as licit drug use.

The schizotypy approach assumes that psychotic symptoms exist along a continuum, with severest symptoms occurring in schizophrenia and mild sub-clinical ones in schizotypal individuals from the general population (15). Schizotypy is commonly assessed using self-report questionnaires $(16,17)$. Scores on these questionnaires can be commonly divided into symptom dimensions known from patients, e.g., consisting of positive schizotypy (e.g., magical thinking, unusual experiences), negative schizotypy (e.g., anhedonia), and cognitive disorganization [e.g., odd speech and behavior; $(16,18)]$. When it comes to laboratory measures, high as compared to low schizotypes yield relatively impaired cognitive performance, e.g., in working memory (19, $20)$, cognitive flexibility (21), and verbal short-term memory (22, 23). Most relevant to our reasoning, high schizotypy goes along with elevated substance use of, e.g., cannabis (24-28), nicotine, and alcohol $(26,29)$. Similarly, an elevated drug use has been reported in schizophrenia when compared to healthy controls $(2,6,30-34)$.

Given the above described interrelationships, it is possible that the link between cannabis and cognition is influenced by individuals' schizotypal features and/or additional licit drug use. The latter reasoning is particularly likely given that $\mathrm{CU}$ show higher consumption of nicotine and/or alcohol when compared to nonusers $(35,36)$. Studies that assessed all three variables (cognition, cannabis use, and schizotypy) found that CU showed both worse cognitive performance and higher schizotypy scores $(24,37)$, and that only in CU schizotypal symptoms correlated with worse cognitive performance (37). When it comes to licit drug use, the available information is even scarcer, as these studies did not report on a potential effect of licit (nicotine, alcohol) drug use (24, 37). We therefore investigated the link between cognitive attenuation and cannabis use in largely pure $\mathrm{CU}$ and non-cannabis users (nCU), accounting for the potential additional influence of both schizotypy and licit drug use (alcohol, nicotine).

We expected that both illicit and licit drug use might be more important than schizotypy to explain variance in cognitive performance (38-40). If schizotypy would additionally or instead explain variance in cognitive performance, we would expect 
the cognitive disorganization dimension (25-27) and/or positive schizotypy dimension $(24,41,42)$ to be more relevant than the negative schizotypy dimension $(27,37,42-44)$ that frequently resulted in heterogeneous findings.

\section{MATERIALS AND METHODS PARTICIPANTS}

We recruited participants via advertisements looking for both pure $\mathrm{CU}$ (see also screening section) and non-nicotine consuming nCU. Advertisements were distributed at the local University and its vicinity on paper and electronically. We also used a local website ("Gumtree"). We recruited 83 healthy native English-speaking participants [ $35 \mathrm{CU}$ (23 males) and $48 \mathrm{nCU}$ (20 males)]. Participants either received monetary compensation for travel expenses or course credits. The University of Bristol ethics committee approved this study. All participants provided written informed consent prior participation.

\section{SCREENING}

In both groups $(\mathrm{CU}, \mathrm{nCU})$, people were excluded if they reported excessive alcohol use ( $>50$ units of alcohol/week for men, $>35$ units of alcohol/women), alcohol use within $12 \mathrm{~h}$ prior to testing, a neurological, psychological, or psychiatric history, or visual problems (including dyslexia). Prior to study inclusion, participants were alerted that we would ask for a urine sample for drug screening. We then asked about illegal substance use within the past 3 months. To encourage honest responding, volunteers were kept unaware of the drug spectrum assessed with the urine test (it detected cannabis metabolites until about 2 weeks after its consumption). To ensure recruitment of largely pure CU, participants were excluded if they indicated regular illicit drug use (apart from cannabis) in the past 3 months (more than twice) and/or use within 2 weeks prior testing. Participants were also asked about their cannabis and nicotine use habits (e.g., average amount of times cannabis used/cigarettes per week) in the past 30 days prior testing. Data with a negative drug test were not excluded if CU self-reported occasional use (on average 1-2 times/week within the past 30 days), and/or indicated regular or frequent use (on average $>2$ times/week in the past 30 days), but not within the past 2 weeks (45). If regular or frequent CU indicated use within the past 2 weeks, participants with a negative drug test were excluded from further analysis. The healthy nCU were excluded if they reported nicotine and cannabis use in the past 30 days, and if they showed a positive drug test.

\section{PROCEDURE}

Participants were firstly screened by means of the procedure outlined above. Subsequently, participants came to the local department for a $1 \mathrm{~h}$ testing session. The $\mathrm{CU}$ were asked to abstain prior testing from (i) cannabis use at least $2 \mathrm{~h}$ and (ii) nicotine use $30 \mathrm{~min}$. We chose this abstinence period for cannabis, because general psychotropic effects seem to taper off $2-3 \mathrm{~h}$ post-consumption (46). In the case of nicotine, acute effects on cognition seem observable within 15-35 min of nicotine consumption [e.g., Ref. $(47,48)]$. After having provided written informed consent, participants underwent the urine test before continuing to the testing session. Participants first completed the drug and schizotypy questionnaires, before performing the cognitive tasks. Participants performed the tasks outlined below as well as a handedness questionnaire and a lateralized lexical decision task. Results from the latter will be presented elsewhere. Task order was randomized between participants. Finally, participants were debriefed and reimbursed for their time.

\section{QUESTIONNAIRES}

\section{Schizotypy}

The Oxford-Liverpool Inventory of Feelings and Experiences (17, 49) is a 159-item self-report instrument consisting of the following sub-scales: positive schizotypy (unusual experiences $=U n E x$, 30 items), negative schizotypy (Introvertive Anhedonia $=$ IntAn, 27 items), and cognitive disorganization ( $=\mathrm{CogDis}, 24$ items). Finally, 23 items assess impulsive non-conformity (ImpNC). Normative values can be found in Mason et al. $(17,49)$. We did not account for IntAn and ImpNC in this study, because of the heterogeneity in findings in the former case (see Introduction) and because ImpNC does not represent a schizotypy dimension (17).

\section{Drug questions}

Participants reported on their prior drug use (lifetime, past year, and past month drug use), e.g., their alcohol, cigarette, cannabis, cocaine, amphetamine, hallucinogen, opiate, and prescribed drug use. Items were taken from the national household survey on drug abuse (50). This questionnaire taps into seven DSM-IV criteria for drug dependence (past 12 months) by asking if people (1) spent a lot of time obtaining, using, or recovering from the drug, (2) experienced a marked increase in amount and frequency of drug use, (3) experienced a marked decrease in the drug effect, and (4) gave up or reduced important social, occupational, or recreational activities due to drug use. It also asks if people experienced (5) drug-induced psychological problems (such as depressive mood), (6) drug-induced physical problems, and (7) a persistent desire for the drug or unsuccessful attempts to stop drug use. For each positive answer, participants received 1 point (maximum score 7) with higher values indicating higher substance use severity. Participants also indicated the average amount of joints/cigarettes per week they used within the past 30 days. For this reason, it is possible that current non-smokers (no tobacco use within the past month) receive a nicotine severity score $\neq 0$ if they have smoked within the past 12 months (this only concerned 2 of the 48 non-smokers).

\section{BEHAVIORAL MEASURES: COGNITIVE FUNCTIONING Trail making task}

The trail making task (TMT) assessed executive functioning (51, 52). In the TMT A, participants connected numbered circles in chronological order (1-25) by drawing a line, as fast as possible. In the subsequent TMT B, participants saw circles containing numbers or letters. They drew a line as quickly as possible in chronological order switching between numbers and letters, i.e., from 1 to A, from A to 2 , from 2 to $\mathrm{B}$, etc. The RT for both versions was recorded. The TMT-index (RT version $B$ minus version A) was used as an estimate of cognitive flexibility (53). Norm values are available from Tombaugh (54). 


\section{Verbal short-term memory (story-recall/logical memory)}

We used a subtest of the revised version of the Wechsler adult intelligence scale (55). The experimenter read out a 60 words story. The participant was asked immediately afterwards to recall as many details as possible (maximum of 23 possible points). Normative data for young adults and university samples can be found in Bowden et al. (56) and Ivison (57), respectively.

\section{Verbal working memory (two-back task)}

Comparable to previous reports $(58,59)$, participants saw 64 sequentially presented digits (ranging from 1 to 9 ) in the middle of the computer screen (white on black background, font Arial, size 16). Participants had to press a given response key when the current digit $(n)$ was identical to the digit $n-2$ (target trials). In all non-target trials, participants had to press another response key. Response key allocation was counterbalanced between participants. A third of the trials $(n=20)$ were target trials, and the remaining trials were non-target trials [ $n=44$; e.g., 59]. To increase task difficulty, we added intrusion trials. These were included to prevent restarting memorization after each successful target identification. Consequently, targets could occur twice in a row. Each stimulus appeared for $2000 \mathrm{~ms}$, with an inter-stimulus interval of $500 \mathrm{~ms}$ (60) before the next digit appeared. Participants had to respond within $2500 \mathrm{~ms}$, otherwise the trial was counted as an omission. All participants performed 16 practice trials. We measured the percentage of the correctly identified targets, as well as mean RTs for correct trials $(59,61)$.

As an additional note, we also measured a computerized Go NoGo task. Due to an overall ceiling performance, we omitted this task from further analysis.

\section{DATA ANALYSIS}

To determine if cannabis use affects cognitive functioning, we conducted separate univariate ANOVAs with group (CU, nCU) as between-subjects factor on the following measures: percentage of correct responses [(number of correctly identified target stimuli $\times 100) /$ total of targets] and RT in the two-back task, TMTindex, and the percentage of correctly identified units in the storyrecall task [(number of correctly identified units $\times 100) /$ total of units)].

To determine effects of drug use and schizotypy on cognition, we firstly investigated the demographic characteristics of our population. We found sex differences between drug groups (see Results for details). We then correlated all variables with the outcome measures to preselect variables for the regression model (see Results for details). Neither age nor schizotypy significantly correlated with the cognitive measures. Due to the previous literature (see Introduction), we nevertheless kept UnEx scores and CogDis scores for the hierarchical regressions as follows: sex was entered in the first step, schizotypy (UnEx scores, CogDis scores) in the second step, and drug use severity (nicotine, alcohol, and cannabis) in the third step. Severity was preferred over frequency due to the former measure's relevance to clinical addiction. Exploratory analysis confirmed that drug use severity was more important than drug use frequency in the current regression analyses. Thus, three blocks of predictors were entered in nested blocks, meaning that each subsequent block contained all prior predictors and the additional predictors from the current block. Presentation of results only includes the new predictors entered, for economy of presentation. All tolerance values were above 0.2 (62) and all independent variables were mean-centered. Thus, multi-collinearity between the independent variables was considered negligible. The dependent variables were (i) percentage correctly identified targets and mean RT for correctly identified targets and non-targets in the two-back task; (ii) TMT-index; and (iii) percentage of correctly recalled units in the story-recall task.

Kolmogorov-Smirnov tests for the groups separately revealed normal distribution for all behavioral measures. All $p$-values were two-tailed and the $\alpha$-level was set at 0.05 .

\section{RESULTS}

\section{PARTICIPANTS}

We identified $35 \mathrm{CU}$ (out of 83 healthy native English-speakers). On average $( \pm S D)$, CU smoked 11.14 joints per week $( \pm 12.16)$, a frequency that can be classified as heavy use [ $>5$ joints per week; (63)]. The last cannabis consumption was on average more than $24 \mathrm{~h}$ ago $(114.37 \pm 143.02 \mathrm{~h})$ with $4 \mathrm{CU}$ reporting cannabis use 2$6 \mathrm{~h}$ before testing. When only individuals are considered whose last cannabis consumption was more than $6 \mathrm{~h}$ ago, the results stayed largely the same. Age of cannabis use onset was at 15.46 years of age $( \pm 1.87$ years $)$. Within the CU group, 13 individuals were educated to college level $(37 \%), 1$ to secondary school (3\%), and 21 to university degrees $(60 \%)$. Of the $48 \mathrm{nCU}, 12$ individuals had college degrees $(25 \%)$ and 36 had university degrees (75\%). A chi-square test indicated that the two groups did not differ from each other in terms of highest finished education level $\left[\chi^{2}(\mathrm{df}=2)=3.03\right.$, $p=0.22]$. A chi-square test on sex distributions showed that significantly more males $(n=23)$ were in the CU group as compared to the nCU group $\left[n=20 ; \chi^{2}(\mathrm{df}=1)=4.69, p=0.03\right]$.

We also compared schizotypy sub-scale scores to a previous normative sample (17) via calculations of Cohen's $d$ (64) with values of $\pm 0.2 / \pm 0.5 / \pm 0.8$ being indicative of a small/medium/large effect size, respectively. As can be seen from Table 1, schizotypy values were largely comparable to normative data, as no large effect sizes were found. A medium effect size was indicated for UnEx, with higher values in the normative sample as compared to the current sample (see Table 1).

As can be seen from Table 2, the groups (CU, nCU) were comparable in age. However, $\mathrm{CU}$ as compared to $\mathrm{nCU}$ scored higher on UnEx (as a trend), nicotine, cannabis, and alcohol use severity

Table 1 | Means, SDs, and effect sizes (Cohen's $d$ ), comparing the values of the normative sample with the current sample.

\begin{tabular}{|c|c|c|c|c|c|}
\hline \multirow[t]{2}{*}{ Questionnaire } & \multicolumn{2}{|c|}{$\begin{array}{l}\text { Norm values } \\
\qquad(N=508)\end{array}$} & \multicolumn{2}{|c|}{$\begin{array}{l}\text { Current sample } \\
\qquad(N=83)\end{array}$} & \multirow[t]{2}{*}{ Cohen's $d$} \\
\hline & Mean & SD & Mean & SD & \\
\hline O-LIFE: UnExa & 9.70 & 6.70 & 6.36 & 4.92 & 0.52 \\
\hline O-LIFE: CogDis ${ }^{b}$ & 11.60 & 5.80 & 10.61 & 5.28 & 0.17 \\
\hline
\end{tabular}

anusual experiences.

${ }^{b}$ Cognitive disorganization. 
(since nCU were screened for weekly cannabis and cigarette use, the comparisons between nCU and $\mathrm{CU}$ were not conducted for these variables).

\section{COGNITIVE FUNCTIONING Group comparisons}

The separate univariate ANOVAs on the outcome measures revealed that $\mathrm{CU}$ performed significantly worse in the story-recall task, and slightly worse on the working memory task as compared to nCU (Table 3). The results for the remaining outcome variables were not significant (Table 3 ).

\section{Regression analyses}

The initial correlation analyses between task performances, schizotypy sub-scale scores, age, and drug measures revealed that neither age nor schizotypy related to cognitive functioning (all $p$-values $>0.10$, see Table 4). Accordingly, age was not further considered.

Table 2 | Age, schizotypy, and drug use statistics comparing CU and nCU

\begin{tabular}{|c|c|c|c|c|c|c|}
\hline \multirow[t]{2}{*}{ Variables } & \multicolumn{2}{|c|}{$\mathrm{CU}^{\mathrm{c}}(N=35)$} & \multicolumn{2}{|c|}{$n C U^{d}(N=48)$} & \multirow[t]{2}{*}{$t$} & \multirow[t]{2}{*}{$p$} \\
\hline & Mean & SD & Mean & SD & & \\
\hline Age & 22.51 & 5.63 & 21.67 & 3.56 & 0.84 & 0.40 \\
\hline UnExa & 7.63 & 6.04 & 5.44 & 3.71 & 1.90 & 0.06 \\
\hline CogDis ${ }^{b}$ & 10.46 & 5.75 & 10.73 & 4.97 & -0.23 & 0.82 \\
\hline Cigarettes/week & 24.66 & 28.67 & $\mathrm{n} / \mathrm{a}$ & n/a & $\mathrm{n} / \mathrm{a}$ & $\mathrm{n} / \mathrm{a}$ \\
\hline Joints/week & 11.14 & 12.16 & n/a & n/a & n/a & $\mathrm{n} / \mathrm{a}$ \\
\hline Nicotine use severity & 1.94 & 1.86 & 0.08 & 0.45 & 5.78 & 0.00 \\
\hline Cannabis use severity & 2.97 & 1.95 & 0.00 & 0.00 & 9.03 & 0.00 \\
\hline Alcohol use severity & 2.29 & 1.84 & 1.31 & 1.42 & 2.72 & 0.01 \\
\hline
\end{tabular}

a Unusual experiences.

${ }^{b}$ Cognitive disorganization.

${ }^{c}$ Cannabis users.

${ }^{d}$ Cannabis non-users.

Values were compared between groups $(\mathrm{CU}, n \mathrm{CU})$ using independent $t$-tests (statistical results are shown in this table; $t$-values, $d f=81, p$-values). Significant group differences are highlighted in bold, trends in gray.
UnEx and CogDis on the other hand were included as a priori predictions were formulated based on the published literature (see Introduction and Data Analysis).

The significant results from the subsequent regression analyses (see Data Analysis for further details) can be seen in Table 5. With regard to the control variables, we found that sex predicted verbal short-term memory. Post hoc independent $t$-tests revealed that women were significantly better than men in the storyrecall task [women: $66.63 \pm 12.08 \%$, men: $m=58.54 \pm 15.39 \%$; $t(81)=2.65, p=0.01]$. Entering schizotypy in the second step explained no additional variance on top of sex (see Table 5). Drug use severity in the third step predicted significant amounts of variance in the outcome measures. Here, higher alcohol use severity predicted lower working memory performance, and higher cannabis use severity predicted reduced verbal short-term memory on top of sex and schizotypy (Table 5).

\section{DISCUSSION}

We investigated whether pure cannabis use hampers cognitive performance, or whether cognitive attenuation is also, or even better explained by associated licit drug use and psychotic-like features (schizotypy). For this purpose, we tested cognitive functions commonly associated with drug use and schizotypy in CU and nCU. The main findings were that (i) $\mathrm{CU}$ as compared to $\mathrm{nCU}$ performed worse on story recall and slightly worse on the two-back task, but not on the TMT, (ii) CU scored higher than nCU on positive schizotypy (as a trend), and drug use other than cannabis, (iii) regression analyses showed that enhanced cannabis use predicted decreased verbal short-term memory, whereas enhanced alcohol use predicted reduced working memory performance, (iv) none of the schizotypy sub-scales explained any additional variance in cognitive functioning. The implications of these findings are discussed below.

\section{ROLE OF CANNABIS USE SEVERITY}

Our results showed that $\mathrm{CU}$ performed worse than nCU on tasks measuring verbal short-term memory (story recall), and higher cannabis use severity was associated with worse performance in this task. Our results also showed that these relatively negative cognitive implications were not associated with individuals' selfreported schizotypy. The observation that worse story recall is

Table 3 | Descriptive and statistical values for the cognitive measures, comparing performance of $\mathrm{CU}$ and $\mathbf{n C U}$.

\begin{tabular}{|c|c|c|c|c|c|c|c|}
\hline \multirow[t]{2}{*}{ Variables } & \multicolumn{2}{|c|}{$\mathrm{CU}^{\mathrm{b}}(N=35)$} & \multicolumn{2}{|c|}{$\mathrm{nCU}^{\mathrm{c}}(N=48)$} & \multirow[t]{2}{*}{$F(1,81)$} & \multirow[t]{2}{*}{$p$} & \multirow[t]{2}{*}{ Partial $\eta^{2}$} \\
\hline & Mean & SD & Mean & SD & & & \\
\hline Two-back \% target correct & 86.00 & 13.49 & 90.52 & 8.07 & 3.62 & 0.06 & 0.04 \\
\hline Two-back mean RT & 822.57 & 164.00 & 821.42 & 205.92 & 0.00 & 0.98 & $<0.01$ \\
\hline $\mathrm{TMT}^{\mathrm{a}}$ index & 23.77 & 13.58 & 23.56 & 16.58 & 0.00 & 0.95 & $<0.01$ \\
\hline Story-recall \% correct & 55.90 & 14.78 & 67.21 & 12.19 & 14.55 & $<0.01$ & 0.15 \\
\hline
\end{tabular}

${ }^{a}$ Trail making task.

${ }^{b}$ Cannabis users.

${ }^{c}$ Cannabis non-users.

Values were compared with univariate ANOVAs, and significant values are highlighted in bold, trends in gray. 
associated with cannabis use is in line with previous studies $(3,13$, 46). However, story recall (verbal memory) was the only task that was affected by cannabis use, whereas relatively impaired performance on another cognitive task (working memory as assessed with the two-back task) was related to enhanced alcohol use instead. Previous studies have indicated that cannabis use has a negative impact on working memory performance $(46,65)$ and mental flexibility $(3,66)$ as well. Our findings suggest that these previous findings on cannabis use were potentially confounded by concomitant non-excessive alcohol use $(3,67)$.

Despite some evidence that cannabis use is still associated with cognitive impairments after adjusting for alcohol use (68), independent studies $(8,36)$ report that $\mathrm{CU}$ tend to consume higher amounts of other drugs as well. This additional drug use, as frequently not assessed, might lead to misleading conclusions

Table 4 | Correlations between potential predictor variables and cognitive measures.

\begin{tabular}{lcccc}
\hline Variables & $\begin{array}{l}\text { Two-back task } \\
\text { \% target correct }\end{array}$ & $\begin{array}{l}\text { Two-back task } \\
\text { mean RT }\end{array}$ & $\begin{array}{l}\text { TMTc } \\
\text { index }\end{array}$ & $\begin{array}{l}\text { Story-recall } \\
\text { \% correct }\end{array}$ \\
\hline Age & -0.06 & -0.16 & -0.08 & -0.03 \\
UnExa & -0.08 & 0.06 & 0.08 & -0.03 \\
CogDis & 0.02 & -0.01 & -0.04 & -0.07 \\
Nicotine & $-\mathbf{0 . 2 4}^{*}$ & 0.08 & 0.04 & $-\mathbf{0 . 4 1}^{* *}$ \\
use severity & & & & \\
Cannabis & $-\mathbf{0 . 2 7}^{*}$ & 0.14 & 0.10 & $-\mathbf{0 . 4 7}^{* *}$ \\
use severity & & & & \\
Alcohol use & $-\mathbf{0 . 2 9 * *}^{*}$ & $\mathbf{0 . 4 0 * *}$ & $\mathbf{0 . 2 8 * *}$ & -0.07 \\
severity & & & &
\end{tabular}

a Unusual experiences.

${ }^{b}$ Cognitive disorganization.

${ }^{c}$ Trail making task.

* Significant at $p \leq 0.05$.

** Significant at $p \leq 0.01$.

*** Significant at $p \leq 0.001$.

Significant values are highlighted in bold. about cannabis effects on cognition. Particularly licit drug use like alcohol seems to be a relevant confounding factor. For instance, whereas in some studies alcohol use is either statistically controlled for (63) or subjects with alcohol abuse are excluded from participating $(13,14)$, other studies do not account for this variable (24, $69,70,71)$. Moreover, alcohol and cannabis are thought to exert comparable effects on cognition, i.e., cognitive attenuation in verbal memory (72-74), cognitive flexibility $(75,76)$, and working memory (77-79). Future studies should consider (non-excessive) licit drug use as a potential confounding factor when investigating the effects of cannabis use on cognition.

\section{ROLE OF SCHIZOTYPY}

Of additional significance was the observation that schizotypy did not explain variance in most cognitive tasks. We do not think that this finding can be explained by deviant features of our sample, because we replicated many previous observations, i.e., that $\mathrm{CU}$ as compared to nCU scored slightly higher on measures of positive schizotypy $(24,27,28,41,42,44)$. The observation that schizotypy was not importantly related to cognitive functioning would indicate that the impairments in, e.g., working memory $(19,20)$, cognitive flexibility $(21)$, and verbal memory $(22,23)$ may be influenced by individuals' concomitant drug use.

Unfortunately, the above mentioned studies did not report on drug use $(19,21-23,80)$, or only screened for substance use history without specifying the substances controlled for $(20,81)$. It is thus possible that substances (e.g., illicit as well as licit) influenced the relationship between schizotypal symptoms and the cognitive functions assessed in these experiments (38-40). In particular, our results suggest that cannabis may be more relevant than schizotypy for cognitive attenuations in verbal short-term memory, and alcohol may be more relevant than schizotypy for cognitive attenuations in working memory (82).

The specific cannabis effects on story recall, but not on the two-back or TMT may also suggest that not all cognitive functions are equally sensitive to cannabis-related attenuations. Even though many studies observe $\mathrm{CU}$ to show impairments compared to nCU on tasks measuring working memory (46) and mental flexibility $(3,66)$, this may not always be the case $(71,83)$. In fact, different

Table 5 | Significant results (including trends in gray) from the regression analyses assessing the effect of sex (step 1), schizotypy (UnEx ${ }^{a}$, CogDis ${ }^{b}$; step 2), and drug use severity (nicotine, alcohol, and cannabis; step 3) on cognitive measures.

\begin{tabular}{|c|c|c|c|c|c|c|}
\hline Outcome variables & Step & Significant predictor & $\beta$-value & Total $R^{2}$ & $\Delta R^{2}$ & $F$ for $\Delta R^{2}$ \\
\hline Two-back \% target correct & 3 & Alcohol & $-0.25^{*}$ & $0.15^{* *}$ & $0.14^{* *}$ & $4.25^{* *}$ \\
\hline Two-back mean RT & 1 & Sex & $-0.21^{\dagger}$ & $0.04^{\dagger}$ & $0.04^{\dagger}$ & $3.61^{\dagger}$ \\
\hline \multirow[t]{2}{*}{ Story-recall \% correct } & 1 & Sex & $0.28^{* *}$ & $0.08^{* *}$ & $0.08^{* *}$ & $7.02^{* *}$ \\
\hline & 3 & Cannabis & $-0.41 * *$ & $0.30 * * *$ & $0.21 * * *$ & $7.46^{* * *}$ \\
\hline
\end{tabular}

${ }^{+} p \leq 0.10$.

* Significant at $p \leq 0.05$.

* ${ }^{*}$ Significant at $p \leq 0.01$.

*** Significant at $p \leq 0.001$.

a Unusual experiences.

${ }^{b}$ Cognitive disorganization. 
meta-analyses draw inconsistent conclusions about which cognitive functions qualify as cognitive markers, or endophenotypes for pathological changes. Findings are inconsistent in CU and along the schizophrenia spectrum, with some studies pointing to verbal memory impairments in both populations $(65,84-86)$, some pointing to cognitive flexibility impairments $(86,87)$, and others reporting consistent working memory impairments in both patients with psychosis and CU $(65,85,86)$. Alternatively, higher THC-content of used cannabis may relate to more prominent cognitive attenuations (88). Therefore, future studies should report the type and/or strength of cannabis used to improve reliability of findings.

Admittedly, all these complex functions tap into a variety of cognitive sub-functions. For this reason, to increase reliability of findings across studies and populations, the research community might consider behavioral markers that are less complex in their cognitive demands (89-92). Additionally, the pathophysiology of psychotic disorders is currently unknown, and the disorders are quite heterogeneous in their phenotypic expression. Consequently, we may increase the reliability of findings by accounting for seemingly related as well as unrelated factors potentially influencing the relationship between cannabis, cognition, and psychosis (risk). For instance, studies could consider different yet potentially equally relevant personality traits such as those tapping on the autism spectrum (93) or the bipolar spectrum $(94,95)$. Beyond personality, studies could consider genetic predisposition (96), IQ (97), and neurochemical peculiarities such as dopamine receptor availability $(98,99)$ that may influence the effect cannabis exerts on cognition. Such factors are also relevant for the link between psychosis and drug use, e.g., genetic predisposition (100, 101), IQ (102-104), and neurochemical peculiarities (99). At present, it is impossible to account for all putatively influential variables, and hence additional studies need to be conducted to replicate our and similar findings, be it clinical, experimental, and/or epidemiological studies.

\section{STUDY LIMITATIONS AND FUTURE RESEARCH}

In the catchment area of our study, the "binge drinking culture" reflects on the high acceptance for alcohol use (105). Consequently, we refrained from pre-selecting participants according to their alcohol use, as the recruitment of pure CU (rather than polydrug users) turned out to be challenging, and was not facilitated by the modest incentives we could offer. Likewise, controlling for the couse of nicotine seemed even more unavoidable, because cannabis is mostly used in combination with nicotine (106). Yet, controlling for nicotine could have been relevant, because nicotine itself might counteract the effects of cannabis on cognition (33, 107-109). We therefore suggest that future studies should elucidate the role of nicotine and cannabis more directly.

The gender composition differed between groups, a difference common to studies such as the current one. This gender difference could have also affected the group differences in story recall. Typically, females perform better on verbal short-term memory tasks than males (110), a finding also observed here. Since the nCU group consisted of more females than the CU, this group difference could alternatively explain the worse story recall in CU. However, since cannabis use related to worse story-recall performance on top of sex in the regression analysis, we deem it unlikely that the group differences are solely due to effects associated with the unequal sex distribution. Nevertheless, future studies on drug use and cognition should aim to control for sex differences.

A final, frequently mentioned study limitation is the sample size, also relevant to the conducted analyses. For regression analyses, the guidelines for recommended sample sizes vary, from using $50+8 \times N$ variables (111-113) to 10 participants per predictor variable (114). Obviously, a larger sample size would always be advisable. Yet, our sample size matches sample sizes in other studies reporting on preselected minority samples of (relatively) pure drug users (3). A potential reason could be firstly, that these individuals are either extremely difficult to motivate, or secondly, that pure users of drugs are a rarity, at least in our study region. The difficulty of finding pure CU may also be reflected in population descriptions over the last 30 years; many studies inferred on the influence of cannabis use on cognition and mental health risk without necessarily ensuring that individuals did not also consume other licit and illicit drugs. We thus face the future challenge to disentangle the impact of a specific drug use or synergetic drug uses on cognition and mental health (115-117).

Finally, cognitive attenuations related to cannabis use seem more overt in heavy as compared to moderate or light users (14, $118,119)$. A higher frequency of cannabis use in our sample might have exacerbated the reported cognitive attenuations. Though definitions for heavy use may vary $(118,119)$, the frequency of cannabis use (joints/week) in our sample seems to indicate heavy use according to a previous report on pure CU (63). To note, our data point to a negligible influence of frequency of pure cannabis use (see Materials and Methods).

\section{CONCLUSION}

While pure cannabis and alcohol use seem associated with adverse effects on cognition, other risk factors (e.g., nicotine use) might also be relevant. Schizotypy, on the other hand, seems unrelated to cognitive attenuation. Results stress the importance to control for additional substance use (and non-excessive use in particular), whether illicit or licit, when assessing the effect of schizotypal symptoms and/or cannabis use on cognition. Moreover, heterogeneity of cannabis-related attenuations of specific cognitive functions may be avoided by controlling for additional factors potentially influencing the relationship between cannabis, cognition, and psychosis (-risk).

\section{AUTHOR CONTRIBUTIONS}

All authors significantly contributed to the conception or design of the work, the analysis, and interpretation of data for the work, as well as revising it critically for important intellectual content. Dr. Daniela A. Herzig was additionally involved in the data acquisition and drafting the first version of the manuscript. All authors approve of the final version of the manuscript, therefore, ensuring that questions related to the accuracy or integrity of any part of the work are appropriately investigated and resolved.

\section{ACKNOWLEDGMENTS}

Participant payment was provided by the University of Bristol. Part of the payment was derived from Prof. Christine Mohr's personal 
budget at the University of Bristol, and part from the University of Bristol Psychopharmacology Unit. The funding source had no additional role other than financial support. All authors contributed in a significant way to the manuscript and all authors have read and approved the final manuscript. There are no conflicts of interest with the present manuscript. The author would also like to thank Prof. Marcus Munafo and Dr. Stanley Zammit for their support, in particular, their aid when acquiring ethical approval for this study.

\section{REFERENCES}

1. European Monitoring Centre for Drugs and Drug Addiction. European Drug Report 2014: Trends and Developments (2014). Available from: http://www. emcdda.europa.eu/publications/edr/trends-developments/2014

2. Barkus E, Murray RM. Substance use in adolescence and psychosis: clarifying the relationship. Annu Rev Clin Psychol (2010) 6:365-89. doi:10.1146/annurev. clinpsy.121208.131220

3. Fernández-Serrano MJ, Pérez-García M, Verdejo-García A. What are the specific vs. generalized effects of drugs of abuse on neuropsychological performance? Neurosci Biobehav Rev (2011) 35:377-406. doi:10.1016/j.neubiorev. 2010.04.008

4. Arseneault L, Cannon M, Poulton R, Murray R, Caspi A, Moffitt TE. Cannabis use in adolescence and risk for adult psychosis: longitudinal prospective study. Br Med J (2002) 325:1212-3. doi:10.1136/bmj.325.7374.1212

5. van Os J, Bak M, Hanssen M, Bijl RV, De Graaf R, Verdoux H. Cannabis use and psychosis: a longitudinal population-based study. Am J Epidemiol (2002) 156:319-27. doi:10.1093/aje/kwf043

6. Zammit S, Allebeck P, Andreasson S, Lundberg I, Lewis G. Self reported cannabis use as a risk factor for schizophrenia in Swedish conscripts of 1969: historical cohort study. Br Med J (2002) 325:1199-201. doi:10.1136/bmj.325. 7374.1199

7. Casadio P, Fernandes C, Murray RM, Di Forti M. Cannabis use in young people: the risk for schizophrenia. Neurosci Biobehav Rev (2011) 35:1779-87. doi:10.1016/j.neubiorev.2011.04.007

8. Schimmelmann BG, Conus P, Cotton S, Kupferschmid S, Mcgorry PD, Lambert M. Prevalence and impact of cannabis use disorders in adolescents with early onset first episode psychosis. Eur Psychiatry (2012) 27:463-9. doi:10.1016/j.eurpsy.2011.03.001

9. Parakh P, Basu D. Cannabis and psychosis: have we found the missing links? Asian J Psychiatr (2013) 6:281-7. doi:10.1016/j.ajp.2013.03.012

10. Manrique-Garcia E, Zammit S, Dalman C, Hemmingsson T, Andreasson S, Allebeck P. Cannabis, schizophrenia and other non-affective psychoses: 35 years of follow-up of a population-based cohort. Psychol Med (2012) 42:1321-8. doi:10.1017/S0033291711002078

11. Moore THM, Zammit S, Lingford-Hughes A, Barnes TRE, Jones PB, Burke M, et al. Cannabis use and risk of psychotic or affective mental health outcomes: a systematic review. Lancet (2007) 370:319-28. doi:10.1016/S0140-6736(07) 61162-3

12. Solowij N, Battisti R. The chronic effects of cannabis on memory in humans: a review. Curr Drug Abuse Rev (2008) 1:81-98. doi:10.2174/ 1874473710801010081

13. Wagner D, Becker B, Gouzoulis-Mayfrank E, Daumann J. Interactions between specific parameters of cannabis use and verbal memory. Prog Neuropsychopharmacol Biol Psychiatry (2010) 34:871-6. doi:10.1016/j.pnpbp.2010.04.004

14. Pope HG, Yurgelun-Todd D. The residual cognitive effects of heavy marijuana use in college students. JAMA (1996) 275:521-7. doi:10.1001/jama.275.7.521

15. Meehl PE. Schizotaxia, schizotypy, schizophrenia. Am Psychol (1962) 17:827-38. doi:10.1037/h0041029

16. Raine A. The SPQ: a scale for the assessment of schizotypal personality based on DSM-III-R criteria. Schizophr Bull (1991) 17:555-64. doi:10.1093/schbul/ 17.4.555

17. Mason O, Claridge G, Jackson M. New scales for the assessment of schizotypy. Pers Individ Dif (1995) 18:7-13. doi:10.1016/0191-8869(94)00132-C

18. Liddle PF. The symptoms of chronic schizophrenia. A re-examination of the positive-negative dichotomy. Br J Psychiatry (1987) 151:145-51. doi:10.1192/ bjp.151.2.145
19. Park S, McTigue K. Working memory and the syndromes of schizotypal personality. Schizophr Res (1997) 26:213-20. doi:10.1016/S0920-9964(97)00051-0

20. Pflueger MO, Gschwandtner U, Stieglitz R-D, Riecher-Rössler A. Neuropsychological deficits in individuals with an at risk mental state for psychosis working memory as a potential trait marker. Schizophr Res (2007) 97:14-24. doi:10.1016/j.schres.2007.09.003

21. Giraldez SL, Caro MI, Rodrigo AML, Pineiro MP, Gonzalez JLB. Assessment of essential components of schizotypy by means of neurocognitive measures. Psicothema (1999) 11:477-94.

22. Langdon R, Coltheart M. Recognition of metaphor and irony in young adults: the impact of schizotypal personality traits. Psychiatry Res (2004) 125:9-20. doi:10.1016/j.psychres.2003.10.005

23. Simon AE, Cattapan-Ludewig K, Zmilacher S, Arbach D, Gruber K, Dvorsky $\mathrm{DN}$, et al. Cognitive functioning in the schizophrenia prodrome. Schizophr Bull (2007) 33:761-71. doi:10.1093/schbul/sbm018

24. Skosnik PD, Spatz-Glenn L, Park S. Cannabis use is associated with schizotypy and attentional disinhibition. Schizophr Res (2001) 48:83-92. doi:10.1016/ S0920-9964(00)00132-8

25. Barkus E, Lewis S. Schizotypy and psychosis-like experiences from recreational cannabis in a non-clinical sample. Psychol Med (2008) 38:1267-76. doi:10.1017/S0033291707002619

26. Esterberg ML, Goulding SM, Mcclure-Tone EB, Compton MT. Schizotypy and nicotine, alcohol, and cannabis use in a non-psychiatric sample. Addict Behav (2009) 34:374-9. doi:10.1016/j.addbeh.2008.11.007

27. Cohen AS, Buckner JD, Najolia GM, Stewart DW. Cannabis and psychometrically-defined schizotypy: use, problems and treatment considerations. J Psychiatr Res (2011) 45:548-54. doi:10.1016/j.jpsychires.2010.08.013

28. Fridberg DJ, Vollmer JM, O'Donnell BF, Skosnik PD. Cannabis users differ from non-users on measures of personality and schizotypy. Psychiatry Res (2011) 186:46-52. doi:10.1016/j.psychres.2010.07.035

29. Larrison AL, Briand KA, Sereno AB. Nicotine, caffeine, alcohol and schizotypy. Pers Individ Dif (1999) 27:101-8. doi:10.1016/S0191-8869(98)00217-7

30. Cantor-Graae E, Nordström LG, Mcneil TF. Substance abuse in schizophrenia: a review of the literature and a study of correlates in Sweden. Schizophr Res (2001) 48:69-82. doi:10.1016/S0920-9964(00)00114-6

31. de Leon J, Diaz FJ, Rogers T, Browne D, Dinsmore L. Initiation of daily smoking and nicotine dependence in schizophrenia and mood disorders. Schizophr Res (2002) 56:47-54. doi:10.1016/S0920-9964(01)00217-1

32. Mastrigt S, Addington J, Addington D. Substance misuse at presentation to an early psychosis program. Soc Psychiatry Psychiatr Epidemiol (2004) 39:69-72. doi:10.1007/s00127-004-0713-0

33. Kumari V, Postma P. Nicotine use in schizophrenia: the self medication hypotheses. Neurosci Biobehav Rev (2005) 29:1021-34. doi:10.1016/j. neubiorev.2005.02.006

34. Gregg L, Barrowclough C, Haddock G. Reasons for increased substance use in psychosis. Clin Psychol Rev (2007) 27:494-510. doi:10.1016/j.cpr.2006.09.004

35. Grant BF, Pickering R. The relationship between cannabis use and DSM-IV cannabis abuse and dependence: results from the national longitudinal alcohol epidemiologic survey. J Subst Abuse (1998) 10:255-64. doi:10.1016/S08993289(99)80141-2

36. Degenhardt L, Hall W, Lynskey M. The relationship between cannabis use and other substance use in the general population. Drug Alcohol Depend (2001) 64:319-27. doi:10.1016/S0376-8716(01)00130-2

37. Mass R, Bardong C, Kindl K, Dahme B. Relationship between cannabis use, schizotypal traits, and cognitive function in healthy subjects. Psychopathology (2001) 34:209-14. doi:10.1159/000049309

38. Herzig DA, Tracy J, Munafò M, Mohr C. The influence of tobacco consumption on the relationship between schizotypy and hemispheric asymmetry. J Behav Ther Exp Psychiatry (2010) 41:397-408. doi:10.1016/j.jbtep.2010.04.003

39. Herzig DA, Mohr C. Stressing schizotypy: the modulating role of stressrelieving behaviours and intellectual capacity on functional hemispheric asymmetry. Laterality (2012) 18(2):152-78. doi:10.1080/1357650X.2011.638638

40. Herzig DA, Brooks R, Mohr C. Inferring about individual drug and schizotypy effects on cognitive functioning in polydrug using mephedrone users before and after clubbing. Hum Psychopharmacol (2013) 28:168-82. doi:10. 1002/hup. 2307

41. Verdoux H, Sorbara F, Gindre C, Swendsen JD, Van Os J. Cannabis use and dimensions of psychosis in a nonclinical population of female subjects. Schizophr Res (2003) 59:77-84. doi:10.1016/S0920-9964(01)00401-7 
42. Compton MT, Chien V, Bollini A. Associations between past alcohol, cannabis, and cocaine use and current schizotypy among first-degree relatives of patients with schizophrenia and non-psychiatric controls. Psychiatr Q (2009) 80:143-54. doi:10.1007/s11126-009-9102-x

43. Bailey EL, Swallow BL. The relationship between cannabis use and schizotypal symptoms. Eur Psychiatry (2004) 19:113-4. doi:10.1016/j.eurpsy.2003. 12.001

44. Skosnik PD, Park S, Dobbs L, Gardner WL. Affect processing and positive syndrome schizotypy in cannabis users. Psychiatry Res (2008) 157:279-82. doi:10.1016/j.psychres.2007.02.010

45. Solowij N, Michie PT, Fox AM. Differential impairments of selective attention due to frequency and duration of cannabis use. Biol Psychiatry (1995) 37:731-9. doi:10.1016/0006-3223(94)00178-6

46. Ranganathan M, D'Souza D. The acute effects of cannabinoids on memory in humans: a review. Psychopharmacology (2006) 188:425-44. doi:10.1007/ s00213-006-0508-y

47. Le Houezec J, Halliday R, Benowitz N, Callaway E, Naylor H, Herzig K. A low dose of subcutaneous nicotine improves information processing in nonsmokers. Psychopharmacology (1994) 114:628-34. doi:10.1007/BF02244994

48. Ernst M, Heishman SJ, Spurgeon L, London ED. Smoking history and nicotine effects on cognitive performance. Neuropsychopharmacology (2001) 25:313-9. doi:10.1016/S0893-133X(01)00257-3

49. Mason O, Claridge G. The oxford-Liverpool inventory of feelings and experiences (O-LIFE): further description and extended norms. Schizophr Res (2006) 82:203-11. doi:10.1016/j.schres.2005.12.845

50. United States Department of Health and Human Services. National Household Survey on Drug Abuse. MI: Substance Abuse and Mental Health Services Administration. Office of Applied Studies. Inter-university Consortium for Political and Social Research (1998). Available from: www.icpsr.umich.edu

51. Army Individual Test Battery. Manual of Directions and Scoring. Washington, DC: War Department, Adjutant General's Office (1944).

52. Reitan RM, Wolfson D. The Halstead-Reitan Neuropsychological Test Battery: Theory and Clinical Interpretation. Tucson, AZ: Neuropsychology Press (1985).

53. Lezak MD. Neuropsychological Assessment. 3rd ed. New York, NY: Oxford (1995).

54. Tombaugh TN. Trail making test A and B: normative data stratified by age and education. Arch Clin Neuropsychol (2004) 19:203-14. doi:10.1016/S08876177(03)00039-8

55. Wechsler D. Manual for the Wechsler Memory Scale-Revised. San Antonio, TX: The Psychological Corporation (1987).

56. Bowden SC, Carstairs JR, Shores EA. Confirmatory factor analysis of combined Wechsler adult intelligence scale - revised and Wechsler memory scale revised scores in a healthy community sample. Psychol Assess (1999) 11:339-44. doi:10.1037/1040-3590.11.3.339

57. Ivison D. Logical memory in the Wechsler memory scales: does the order of passages affect difficulty in an university sample? Clin Neuropsychol (1993) 7:215-8. doi:10.1080/13854049308401525

58. Owen AM, Mcmillan KM, Laird AR, Bullmore E. N-back working memory paradigm: a meta-analysis of normative functional neuroimaging studies. Hum Brain Mapp (2005) 25:46-59. doi:10.1002/hbm.20131

59. Schoofs D, Preuß D, Wolf OT. Psychosocial stress induces working memory impairments in an N-back paradigm. Psychoneuroendocrinology (2008) 33:643-53. doi:10.1016/j.psyneuen.2008.02.004

60. Barch DM, Sheline YI, Csernansky JG, Snyder AZ. Working memory and prefrontal cortex dysfunction: specificity to schizophrenia compared with major depression. Biol Psychiatry (2003) 53:376-84. doi:10.1016/S0006-3223(02) 01674-8

61. Jonides J, Schumacher EH, Smith EE, Lauber EJ, Awh E, Minoshima S, et al. Verbal working memory load affects regional brain activation as measured by PET. J Cogn Neurosci (1997) 9:462-75. doi:10.1162/jocn.1997.9.4.462

62. Menard S. Applied logistic regression analysis. Thousand Oaks, CA: Sage (1995).

63. Fried PA, Watkinson B, Gray R. Neurocognitive consequences of marihuana - a comparison with pre-drug performance. Neurotoxicol Teratol (2005) 27:231-9. doi:10.1016/j.ntt.2004.11.003

64. Cohen J. A power primer. Psychol Bull (1992) 112:155-9. doi:10.1037/00332909.112.1.155

65. Crean RD, Crane NA, Mason BJ. An evidence-based review of acute and longterm effects of cannabis use on executive cognitive functions. J Addict Med (2011) 5:1-8. doi:10.1097/ADM.0b013e31820c23fa
66. Lundqvist T. Cognitive consequences of cannabis use: comparison with abuse of stimulants and heroin with regard to attention, memory and executive functions. Pharmacol Biochem Behav (2005) 81:319-30. doi:10.1016/j.pbb. 2005.02.017

67. Zeigler DW, Wang CC, Yoast RA, Dickinson BD, Mccaffree MA, Robinowitz CB, et al. The neurocognitive effects of alcohol on adolescents and college students. Prev Med (2005) 40:23-32. doi:10.1016/j.ypmed.2004.04.044

68. Medina KL, Hanson KL, Schweinsburg AD, Cohen-Zion M, Nagel BJ, Tapert SF. Neuropsychological functioning in adolescent marijuana users: subtle deficits detectable after a month of abstinence. J Int Neuropsychol Soc (2007) 13:807-20. doi:10.1017/S1355617707071032

69. Barratt E, Beaver W, White R, Blakeney P, Adams P. The effects of the chronic use of marijuana on sleep and perceptual-motor performance in humans. In: Lewis MF, editor. Current Research in Marijuana. New York: Academic Press (1972). p. 163-93.

70. Pope HG Jr, Gruber AJ, Yurgelun-Todd D. The residual neuropsychological effects of cannabis: the current status of research. Drug Alcohol Depend (1995) 38:25-34. doi:10.1016/0376-8716(95)01145-O

71. Grant JE, Chamberlain SR, Schreiber L, Odlaug BL. Neuropsychological deficits associated with cannabis use in young adults. Drug Alcohol Depend (2012) 121:159-62. doi:10.1016/j.drugalcdep.2011.08.015

72. Petros TV, Kerbel N, Beckwith BE, Sacks G, Sarafolean M. The effects of alcohol on prose memory. Physiol Behav (1985) 35:43-6. doi:10.1016/0031-9384(85) 90169-6

73. Parada M, Corral M, Caamaño-Isorna F, Mota N, Crego A, Holguín SR, et al. Binge drinking and declarative memory in university students. Alcohol Clin Exp Res (2011) 35:1475-84. doi:10.1111/j.1530-0277.2011.01484.x

74. Poltavski DV, Marino JM, Guido JM, Kulland A, Petros TV. Effects of acute alcohol intoxication on verbal memory in young men as a function of time of day. Physiol Behav (2011) 102:91-5. doi:10.1016/j.physbeh.2010.10.007

75. Guillot CR, Fanning JR, Bullock JS, Mccloskey MS, Berman ME. Effects of alcohol on tests of executive functioning in men and women: a dose response examination. Exp Clin Psychopharmacol (2010) 18:409-17. doi:10.1037/a0021053

76. Lyvers M, Tobias-Webb J. Effects of acute alcohol consumption on executive cognitive functioning in naturalistic settings. Addict Behav (2010) 35:1021-8. doi:10.1016/j.addbeh.2010.06.022

77. Weissenborn R, Duka T. Acute alcohol effects on cognitive function in social drinkers: their relationship to drinking habits. Psychopharmacology (Berl) (2003) 165:306-12. doi:10.1007/s00213-002-1281-1

78. Yücel M, Lubman DI, Solowij N, Brewer WJ. Understanding drug addiction: a neuropsychological perspective. Aust N Z J Psychiatry (2007) 41:957-68. doi:10.1080/00048670701689444

79. Crego A, Rodriguez-Holguín S, Parada M, Mota N, Corral M, Cadaveira F. Reduced anterior prefrontal cortex activation in young binge drinkers during a visual working memory task. Drug Alcohol Depend (2010) 109:45-56. doi:10.1016/j.drugalcdep.2009.11.020

80. Tsakanikos E, Claridge G. More words, less words: verbal fluency as a function of 'positive' and 'negative' schizotypy. Pers Individ Dif (2005) 39:705-13. doi:10.1016/j.paid.2005.02.019

81. Koychev I, Mcmullen K, Lees J, Dadhiwala R, Grayson L, Perry C, et al. A validation of cognitive biomarkers for the early identification of cognitive enhancing agents in schizotypy: a three-center double-blind placebo-controlled study. Eur Neuropsychopharmacol (2012) 22:469-81. doi:10.1016/j.euroneuro.2011. 10.005

82. Thoma RJ, Monnig MA, Lysne PA, Ruhl DA, Pommy JA, Bogenschutz $\mathrm{M}$, et al. Adolescent substance abuse: the effects of alcohol and marijuana on neuropsychological performance. Alcohol Clin Exp Res (2011) 35:39-46. doi:10.1111/j.1530-0277.2010.01320.x

83. Solowij N, Stephens RS, Roffman RA, Babor T, Kadden R, Miller M, et al. Cognitive functioning of long-term heavy cannabis users seeking treatment. JAMA (2002) 287:1123-31. doi:10.1001/jama.287.9.1123

84. Heinrichs RW. Meta-analysis and the science of schizophrenia: variant evidence or evidence of variants? Neurosci Biobehav Rev (2004) 28:379-94. doi:10.1016/j.neubiorev.2004.06.003

85. Solowij N, Michie PT. Cannabis and cognitive dysfunction: Parallels with endophenotypes of schizophrenia? J Psychiatry Neurosci (2007) 32:30-52.

86. Mesholam-Gately RI, Giuliano AJ, Goff KP, Faraone SV, Seidman LJ. Neurocognition in first-episode schizophrenia: a meta-analytic review. Neuropsychology (2009) 23:315-36. doi:10.1037/a0014708 
87. Sitskoorn MM, Aleman A, Ebisch SJH, Appels MCM, Kahn RS. Cognitive deficits in relatives of patients with schizophrenia: a meta-analysis. Schizophr Res (2004) 71:285-95. doi:10.1016/j.schres.2004.03.007

88. Solowij N, Pesa N. Cannabis and cognition: Short- and long-term effects. In: Castle DJ, Murray RM, D’Souza CD, editors. Marijuana and Madness. (Vol. 2), Cambridge: Cambridge University Press (2012). p. 91-102.

89. Silverstein SM, Raulin ML, Pristach EA, Pomerantz JR. Perceptual organization and schizotypy. J Abnorm Psychol (1992) 101:265-70. doi:10.1037/0021-843X. 101.2.265

90. Cadenhead KS, Geyer MA, Braff DL. Impaired startle-prepulse inhibition and habituation in patients with schizotypal personality disorder. Am J Psychiatry (1993) 150:1862-7.

91. Ettinger U, Kumari V, Crawford TJ, Corr PJ, Das M, Zachariah E, et al. Smooth pursuit and antisaccade eye movements in siblings discordant for schizophrenia. J Psychiatr Res (2004) 38:177-84. doi:10.1016/S0022-3956(03) 00105-5

92. Cappe C, Herzog MH, Herzig DA, Brand A, Mohr C. Cognitive disorganisation in schizotypy is associated with deterioration in visual backward masking. Psychiatry Res (2012) 200:652-9. doi:10.1016/j.psychres.2012.07.001

93. Dinsdale NL, Hurd PL, Wakabayashi A, Elliot M, Crespi BJ. How are autism and schizotypy related? Evidence from a non-clinical population. PLoS One (2013) 8:e63316. doi:10.1371/journal.pone.0063316

94. Schürhoff F, Laguerre A, Szöke A, Méary A, Leboyer M. Schizotypal dimensions: continuity between schizophrenia and bipolar disorders. Schizophr Res (2005) 80:235-42. doi:10.1016/j.schres.2005.07.009

95. Claridge G, Blakey S. Schizotypy and affective temperament: relationships with divergent thinking and creativity styles. Pers Individ Dif (2009) 46:820-6. doi:10.1016/j.paid.2009.01.015

96. Ho B-C, Wassink TH, Ziebell S, Andreasen NC. Cannabinoid receptor 1 gene polymorphisms and marijuana misuse interactions on white matter and cognitive deficits in schizophrenia. Schizophr Res (2011) 128:66-75. doi:10.1016/j.schres.2011.02.021

97. Pope HG, Gruber AJ, Hudson JI, Cohane G, Huestis MA, Yurgelun-Todd D. Early-onset cannabis use and cognitive deficits: what is the nature of the association? Drug Alcohol Depend (2003) 69:303-10. doi:10.1016/S0376-8716(02) 00334- 4

98. Bossong MG, Van Berckel BN, Boellaard R, Zuurman L, Schuit RC, Windhorst AD, et al. Delta 9-tetrahydrocannabinol induces dopamine release in the human striatum. Neuropsychopharmacology (2009) 34:759-66. doi:10.1038/ npp. 2008.138

99. Kuepper R, Morrison PD, Van Os J, Murray RM, Kenis G, Henquet C. Does dopamine mediate the psychosis-inducing effects of cannabis? A review and integration of findings across disciplines. Schizophr Res (2010) 121:107-17. doi:10.1016/j.schres.2010.05.031

100. Caspi A, Moffitt TE, Cannon M, Mcclay J, Murray R, Harrington H, et al. Moderation of the effect of adolescent-onset cannabis use on adult psychosis by a functional polymorphism in the catechol-O-methyltransferase gene: longitudinal evidence of a gene X environment interaction. Biol Psychiatry (2005) 57:1117-27. doi:10.1016/j.biopsych.2005.01.026

101. Estrada G, Fatjo-Vilas M, Munoz MJ, Pulido G, Minano MJ, Toledo E, et al. Cannabis use and age at onset of psychosis: further evidence of interaction with COMT Val158Met polymorphism. Acta Psychiatr Scand (2011) 123:485-92. doi:10.1111/j.1600-0447.2010.01665.x

102. Matheson S, Langdon R. Schizotypal traits impact upon executive working memory and aspects of IQ. Psychiatry Res (2008) 159:207-14. doi:10.1016/j. psychres.2007.04.006

103. Leeson VC, Barnes TRE, Hutton SB, Ron MA, Joyce EM. IQ as a predictor of functional outcome in schizophrenia: a longitudinal, four-year study of first-episode psychosis. Schizophr Res (2009) 107:55-60. doi:10.1016/j.schres. 2008.08.014

104. Khandaker GM, Barnett JH, White IR, Jones PB. A quantitative meta-analysis of population-based studies of premorbid intelligence and schizophrenia. Schizophr Res (2011) 132:220-7. doi:10.1016/j.schres.2011.06.017
105. Shelton N, Savell E. The geography of binge drinking: the role of alcoholrelated knowledge, behaviours and attitudes. Results from the health survey for England 2007. Health Place (2011) 17:784-92. doi:10.1016/j.healthplace. 2011.02.004

106. Baggio S, Deline S, Studer J, Mohler-Kuo M, Daeppen J-B, Gmel G. Routes of administration of cannabis used for nonmedical purposes and associations with patterns of drug use. J Adolesc Health (2014) 54:235-40. doi:10.1016/j. jadohealth.2013.08.013

107. Adler LE, Hoffer LD, Wiser A, Freedman R. Normalization of auditory physiology by cigarette smoking in schizophrenic patients. Am J Psychiatry (1993) 150:1856-61.

108. Zabala A, Eguiluz JI, Segarra R, Enjuto S, Ezcurra J, Pinto AG, et al. Cognitive performance and cigarette smoking in first-episode psychosis. Eur Arch Psychiatry Clin Neurosci (2009) 259:65-71. doi:10.1007/s00406-0080835-6

109. Heishman SJ, Kleykamp B, Singleton E. Meta-analysis of the acute effects of nicotine and smoking on human performance. Psychopharmacology (2010) 210:453-69. doi:10.1007/s00213-010-1848-1

110. Kaushanskaya M, Marian V, Yoo J. Gender differences in adult word learning. Acta Psychol (2011) 137:24-35. doi:10.1016/j.actpsy.2011.02.002

111. Green SB. How many subjects does it take to do a regression analysis. Multivariate Behav Res (1991) 26:499-510. doi:10.1207/s15327906mbr2603_7

112. Tabachnik BG, Fidell LS. Using Multivariate Statistics. Needham, MA: Allyn and Bacon (2001)

113. Field AP. Discovering Statistics Using SPSS. London: Sage (2009).

114. Harris RJ. A Primer of Multivariate Statistics. New York, NY: Academic Press (1985).

115. Perez-Reyes M, Hicks RE, Bumberry J, Robert Jeffcoat A, Cook CE. Interaction between marihuana and ethanol: effects on psychomotor performance. Alcohol Clin Exp Res (1988) 12:268-76. doi:10.1111/j.1530-0277.1988. tb00193.x

116. Ronen A, Chassidim HS, Gershon P, Parmet Y, Rabinovich A, Bar-Hamburger $\mathrm{R}$, et al. The effect of alcohol, THC and their combination on perceived effects, willingness to drive and performance of driving and non-driving tasks. Accid Anal Prev (2010) 42:1855-65. doi:10.1016/j.aap.2010.05.006

117. Ramaekers J, Theunissen E, De Brouwer M, Toennes S, Moeller M, Kauert G. Tolerance and cross-tolerance to neurocognitive effects of THC and alcohol in heavy cannabis users. Psychopharmacology (2011) 214:391-401. doi:10.1007/s00213-010-2042-1

118. Block RI, Ghoneim MM. Effects of chronic marijuana use on human cognition. Psychopharmacology (1993) 110:219-28. doi:10.1007/BF02246977

119. Bolla KI, Brown K, Eldreth D, Tate K, Cadet JL. Dose-related neurocognitive effects of marijuana use. Neurology (2002) 59:1337-43. doi:10.1212/01.WNL. 0000031422.66442 .49

Conflict of Interest Statement: The authors declare that the research was conducted in the absence of any commercial or financial relationships that could be construed as a potential conflict of interest.

Received: 31 May 2014; accepted: 09 September 2014; published online: 29 September 2014

Citation: Herzig DA, Nutt DJ and Mohr C (2014) Alcohol and relatively pure cannabis use, but not schizotypy, are associated with cognitive attenuations. Front. Psychiatry 5:133. doi: 10.3389/fpsyt.2014.00133

This article was submitted to Schizophrenia, a section of the journal Frontiers in Psychiatry.

Copyright (c) 2014 Herzig, Nutt and Mohr. This is an open-access article distributed under the terms of the Creative Commons Attribution License (CC BY). The use, distribution or reproduction in other forums is permitted, provided the original author(s) or licensor are credited and that the original publication in this journal is cited, in accordance with accepted academic practice. No use, distribution or reproduction is permitted which does not comply with these terms. 